\title{
Phospholipid-derived fatty acids as chemotaxonomic markers for phytoplankton: application for inferring phytoplankton composition
}

\author{
Nicole A. Dijkman*, Jacco C. Kromkamp \\ Centre for Estuarine and Marine Ecology, Netherlands Institute of Ecology (NIOO-KNAW), PO Box 140, \\ 4400 AC Yerseke, The Netherlands
}

\begin{abstract}
Phospholipid-derived fatty acids (PLFA) are widely used as chemotaxonomic markers in microbial ecology. In this paper we explore the use of PLFA as chemotaxonomic markers for phytoplankton species. The PLFA composition was determined for 23 species relevant to estuarine phytoplankton. The taxonomic groups investigated were Chlorophyceae, Trebouxiophyceae, Prasinophyceae, Bacillariophyceae, Dinophyceae, Cryptophyceae, Rhodophyceae, Pavlovophyceae and Prymnesiophyceae. Most of these taxonomic groups have a characteristic PLFA composition, although a few contain truly unique PLFA biomarkers. The PLFA composition was used to derive species composition and abundance of the phytoplankton in the Scheldt estuary (border region between Belgium and the Netherlands) in April, July and October 2003, using the matrix factorization program CHEMTAX. The results agree well with results from HPLC-derived pigment analysis of the same samples. The advantages of using PLFA instead of pigments, or rather in addition to pigments, are that (1) information on bacteria can be derived in addition to information on photosynthetic taxa, (2) in some cases more or different taxa can be distinguished and (3) the isotopic composition of PLFA can be measured relatively easily, allowing the measurement of group-specific primary production.
\end{abstract}

KEY WORDS: Phytoplankton composition $\cdot$ Phospholipid-derived fatty acids $\cdot$ PLFA $\cdot$ Scheldt estuary Biomarkers · CHEMTAX

\section{INTRODUCTION}

Phytoplankton play an important role in aquatic ecosystems, supplying food and oxygen to other members of the ecosystem. Diverse taxonomic groups, varying in shape, pigmentation, ecological characteristics and evolutionary origin, contribute to the phytoplankton community. The composition and abundance of phytoplankton depend on environmental parameters such as irradiance, temperature, salinity and nutrient availability (e.g. Underwood \& Kromkamp 1999, Badylak \& Phlips 2004). Patterns of phytoplankton distribution are the subject of ongoing research (e.g. Badylak \& Phlips 2004). Progress has been made in the under- standing of species richness and distribution, but the 'paradox of the plankton' as posed by Hutchinson (1961) has still not been fully explained. Probably one of the main reasons why species richness and dynamics are not yet well understood is the fact that most measurements are made on bulk samples and that physiological measurements at the level of a single species or functional groups have been hampered by lack of proper methodology.

Microscopy has been an important tool in the study of species richness and abundance ever since the invention of the microscope. Microscopic analysis allows a precise and elaborate determination of the species present in a water sample. However, accurate 
microscopic enumerations require a trained microscopist and are time-consuming. Furthermore, in most cases, the algae have to be stored and therefore fixed before analysis and not all taxa withstand fixation well (Gieskes \& Kraay 1983). Often, cell numbers are difficult to compare due to large differences in cell size and volume and cell numbers have to be converted to biovolume (e.g. Hillebrand et al. 1999) or carbon (Menden-Deuer \& Lessard 2000), a tedious procedure.

The use of chemotaxonomic markers provides an alternative method for determining phytoplankton composition. Photosynthetic pigments are the best known chemotaxonomic markers for phytoplankton. As HPLC technology advances, more and more pigments can be routinely measured, allowing an increasing number of taxa to be distinguished (e.g. Zapata et al. 2004, Jeffrey \& Wright 2006). In recent years, several studies have compared cell numbers and pigments, and in general a good agreement is found between these 2 methods both in freshwater and marine ecosystems (e.g. Garibotti et al. 2003, Marinho \& Rodrigues 2003). Even groups lacking specific pigments can be detected with the help of pigment ratios using matrix factorization programs such as CHEMTAX (Mackey et al. 1996, Schlüter \& Møhlenberg 2003).

Bacteria are also an important constituent of aquatic ecosystems. Suitable pigment biomarkers are lacking for bacteria, and phospholipid-derived fatty acids (PLFA) have become well-established chemotaxonomic markers (Pinkart et al. 2002, Boschker 2004). Phospholipids are the main cellular membrane lipids to which a large diversity of fatty acids can be esterified. Phospholipids are rapidly degraded following cell death, and therefore PLFA are representative of viable organisms (Pinkart et al. 2002, Drenovsky et al. 2004). Since all known organisms contain phospholipids, this method can be used to derive information on other taxonomic groups as well. A substantial amount of information can be found in the literature on the fatty acid composition of phytoplankton groups (Volkman et al. 1989, Viso \& Marty 1993, Brown et al. 1996, Renaud et al. 2002). However, this comprises nearly exclusively information on total fatty acids, including fatty acids derived from neutral lipids and glycolipids in addition to PLFA. A limited number of papers have used PLFA composition (Boschker et al. 2005) or total lipid derived fatty acid composition (Shin et al. 2000, Reuss \& Poulsen 2002) to describe phytoplankton community structure, usually by looking at individual biomarker PLFA or ratios of PLFA.

The objective of the present study was to elaborate and refine the use of PLFA to determine phytoplankton composition and abundance in natural samples. We have determined the PLFA composition of a number of phytoplankton species relevant to estuarine phytoplankton and used these data to derive group composition and abundance in the Scheldt estuary (border region between Belgium and the Netherlands) from the PLFA composition of particulate suspended matter. The results from this PLFA analysis are compared to similar data derived from the pigment composition of the same samples. In a later paper we will determine the photosynthetic activity of several taxonomic groups by measuring the rate of ${ }^{13} \mathrm{C}$-labeling of individual PLFA (Dijkman et al. unpubl.).

\section{MATERIALS AND METHODS}

Organisms and culture conditions. PLFA composition was determined for a number of species from taxonomic groups relevant to estuarine phytoplankton. Most of these species are regularly observed in the Scheldt estuary (e.g. Koeman et al. 2004) and some were isolated from the Scheldt estuary. Other species were obtained from culture collections. Isolated species were identified to at least the genus level by sequence analysis of the $18 \mathrm{~S}$ rRNA. Table 1 lists the species, strain number and source (where available), and the media in which the species were cultured. Of 23 species examined, 9 were axenic (Table 1). In the non-axenic species, bacterial abundance was low and is considered negligible. The algae were grown at a temperature of $15^{\circ} \mathrm{C}$ and a light intensity of $40 \mu \mathrm{mol}$ photons $\mathrm{m}^{-2} \mathrm{~s}^{-1}$ with a light:dark cycle of 14:10 h. The algae were harvested during the exponential growth phase. We also investigated the PLFA content of a number of cyanobacteria, but these were not included in this study because cyanobacteria were hardly ever encountered in the phytoplankton samples.

Study area and sampling. Field measurements were done in the Scheldt estuary, a well-mixed tidal system in the border region between Belgium and The Netherlands (Fig. 1). Samples of surface water (0 to $1 \mathrm{~m})$ were taken using a Niskin sampler on board the RV 'Luctor'. We sampled 5 stations, with nominal salinities of $0,2,8,18$ and 28 PSU respectively, which covers the full salinity gradient of the estuary. The approximate locations of the sampling stations are indicated on the map. The measurements were done in April, July and October 2003. Each month, the 5 stations were sampled within 3 consecutive days.

Sample treatment. Samples from cultured material were filtered onto precombusted $\left(400^{\circ} \mathrm{C}\right) \mathrm{GF} / \mathrm{F}$ filters (Whatman); field samples were filtered onto precombusted GF6 filters (Schleicher \& Schuell). Samples were frozen immediately in liquid nitrogen. Samples for pigment analysis were stored at $-80^{\circ} \mathrm{C}$ until extraction; PLFA extraction was started immediately. Samples for 
Table 1. Species, growth medium and strain code of algae for which phospholipid-derived fatty acids (PLFA) and pigment composition were determined. F/2: artificial seawater enriched with F/2 nutrients (Guillard \& Ryther, 1962); F/2-Si: identical to F/2, but Si omitted; F/20-FF: Frisian Front filter-sterilized water enriched with F/20 nutrients; BG11: blue-green freshwater medium (Stanier et al. 1971); CCMP: Provasoli-Guillard National Center for Culture of Marine Phytoplankton; PCC: Plymouth Culture Collection; CCY: Culture Collection Yerseke

\begin{tabular}{|c|c|c|c|}
\hline Species & Abbreviation & Medium & Strain code \\
\hline \multicolumn{4}{|l|}{ Trebouxiophyceae (Chlorophyta) } \\
\hline Chlorella autotrophica ${ }^{\mathrm{a}}$ & C.a. & $\mathrm{F} / 2-\mathrm{Si}$ & CCMP 243 \\
\hline Chlorella pyrenoidosa ${ }^{\mathrm{a}}$ & C.p. & BG11 & CCY 9618 \\
\hline \multicolumn{4}{|l|}{ Chlorophyceae (Chlorophyta) } \\
\hline Ankistrodesmus angustus ${ }^{\mathrm{a}}$ & A.a. & BG11 & CCY 9713 \\
\hline Pediastrum sp. ${ }^{\mathrm{a}}$ & $P$. & BG11 & CCY 0339 \\
\hline Scenedesmus sp. ${ }^{\mathrm{a}}$ & $S$. & BG11 & CCY 9708 \\
\hline \multicolumn{4}{|l|}{ Prasinophyceae (Chlorophyta) } \\
\hline Pyramimonas obovata & P.o. & $\mathrm{F} / 2-\mathrm{Si}$ & CCMP 723 \\
\hline Pyramimonas parkeae & P.p. & $\mathrm{F} / 2-\mathrm{Si}$ & CCMP 724 \\
\hline \multicolumn{4}{|c|}{ Bacillariophyceae (Heterokontophyta) } \\
\hline Chaetoceros calcitrans ${ }^{\mathrm{a}}$ & C.C & $\mathrm{F} / 2$ & PCC 537 \\
\hline Coscinodiscus granii & C.g. & $\mathrm{F} / 2$ & CCY 0339 \\
\hline Odontella sinensis & O.s. & $\mathrm{F} / 2$ & CCY 0380 \\
\hline Thalassiosira cf nordenskioeldii & T.n. & $\mathrm{F} / 2$ & CCY 0381 \\
\hline Thalassiosira pseudonana ${ }^{\mathrm{a}}$ & T.p. & $\mathrm{F} / 2$ & CCMP 1013 \\
\hline Thalassiosira punctigera & T.pu. & $\mathrm{F} / 2$ & CCY 0341 \\
\hline \multicolumn{4}{|l|}{ Rhodophyceae (Rhodophyta) } \\
\hline Dixoniella grisea $^{\mathrm{a}}$ & D.g. & $\mathrm{F} / 2-\mathrm{Si}$ & CCY $0204^{\mathrm{b}}$ \\
\hline Porphyridium cruentum ${ }^{\mathrm{a}}$ & P.C. & $\mathrm{F} / 2-\mathrm{Si}$ & \\
\hline \multicolumn{4}{|l|}{ Cryptophyceae (Cryptophyta) } \\
\hline Rhodomonas maculata & R.m. & $\mathrm{F} / 2-\mathrm{Si}$ & CCY $0234^{\mathrm{b}}$ \\
\hline Hemiselmis sp. & $H$ & $\mathrm{~F} / 2-\mathrm{Si}$ & CCY $0379^{\mathrm{b}}$ \\
\hline \multicolumn{4}{|l|}{ Dinophyceae (Dinophyta) } \\
\hline Alexandrium tamarense & A.t. & $\mathrm{F} / 2-\mathrm{Si}$ & CCMP 115 \\
\hline Heterocapsa triquetra & H.t. & $\mathrm{F} / 2-\mathrm{Si}$ & CCMP 448 \\
\hline \multicolumn{4}{|l|}{ Prymnesiophyceae (Haptophyta) } \\
\hline Emiliania huxleyi & E.h. & $\mathrm{F} / 2-\mathrm{Si}$ & CCY 0319 \\
\hline Phaeocystis globosa & P.g. & $\mathrm{F} / 20-\mathrm{FF}$ & \\
\hline Isochrysis sp. & I. & $\mathrm{F} / 2-\mathrm{Si}$ & CCY 9619 \\
\hline \multicolumn{4}{|l|}{ Pavlovophyceae (Haptophyta) } \\
\hline Pavlova lutheri & P.l. & $\mathrm{F} / 2-\mathrm{Si}$ & CCY 991 \\
\hline
\end{tabular}

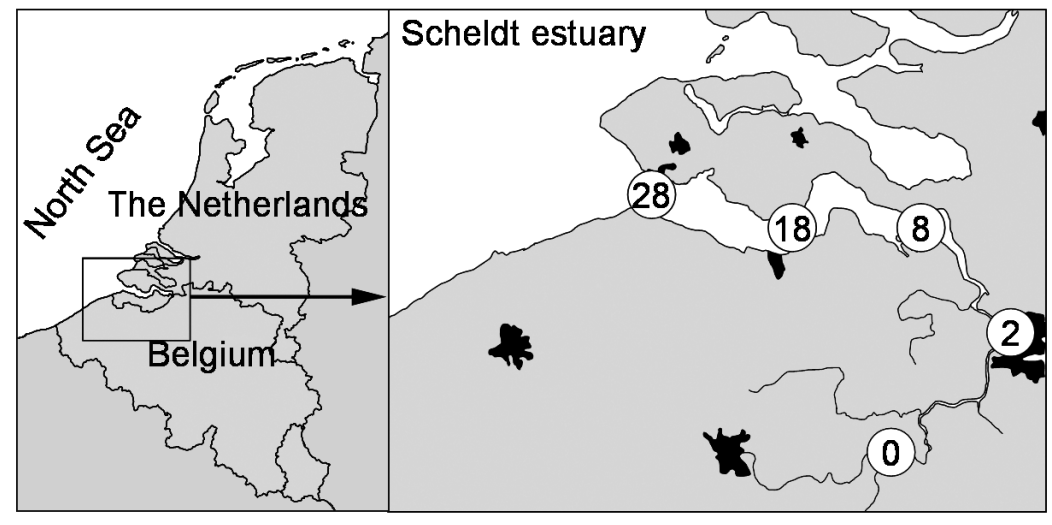

Fig. 1. Scheldt estuary in the border region between Belgium and the Netherlands, showing approximate sampling locations. Exact locations were selected according to salinity and therefore varied with the tide microscopic analysis were preserved with $2 \%$ formaldehyde and stored in the dark at $5^{\circ} \mathrm{C}$. Filters for the analysis of particulate organic carbon (POC) content were stored at $-20^{\circ} \mathrm{C}$ and were dried before determination of the POC content using an elemental analyzer.

PLFA extraction. Total lipids were extracted in a mixture of chloroform, methanol and water (1:2:0.8 by vol.) according to Boschker (2004), using an adaptation of the method of Bligh \& Dyer (1959). Phase separation was induced by the addition of chloroform and water to a final composition of chloroform:methanol:water of 1:1:0.9 (by vol.). The chloroform layer containing the total lipid fraction was collected. This total lipid fraction was fractionated into neutral-, glyco- and phospholipids on heat-activated silicic acid columns (60, Merck ) by sequential elution with chloroform, acetone and methanol. The methanol contained the most polar fraction, which consisted mainly of phospholipids. This fraction was derivatized using mild alkaline methanolysis to yield fatty acid methyl esters (FAME). 12:0 and 19:0 were used as internal FAME standards. FAME concentrations were determined by gas chromatography-flame ionization detection (GCFID, Interscience HRGC MEGA 2 series) using a polar analytical column (Scientific Glass Engineering BPX-70). Identification was based on comparison of retention times with known reference standards and by gas chromatographymass spectrometry (Finnigan Voyager Mass Spectrometer).

Fatty acid notation. Fatty acid notation consists of the number of carbon atoms followed by a colon and the number of double bonds present in the molecule. The position of the first double bond relative to the aliphatic end of the molecule follows the symbol omega, $\omega$ (e.g. 16:1 $\omega 7$ ). The other possible double bonds are methylene interrupted. The prefixes 'i' (iso) and 'ai' (anteiso) represent the location of a methyl branch 1 and 2 carbons, respectively, from the aliphatic end (e.g. i15:0). Where relevant, ' $c$ ' indicates the cis-orientation of the double bonds. 
Pigment analysis. Pigments were extracted in $90 \%$ acetone. Filters and cells were disrupted by shaking with glass pearls in a bead beater, which was cooled using $\mathrm{CO}_{2}$ gas. The slurry was centrifuged and the pigment content of the supernatant was analyzed by HPLC. Pigments were separated on a reverse-phase column (Nova-pak C18; Waters Millennium HPLC system). Gradient mixing pumps delivered 3 mobilephase solvents: methanol/ammonium acetate, $90 \%$ acetonitril and 100\% ethyl acetate (Rijstenbil 2003 and references therein). Pigments were identified and quantified by commercially available standards using both a fluorescence detector (Waters 474 Scanning Fluorescence Detector) and a photodiode array absorption detector (Waters 996 Photodiode Array Detector).

Data analysis. Data were analyzed using the matrixfactorization program CHEMTAX (Mackey et al. 1996). The program uses factor analysis and a steepest descent algorithm to find the best fit to the data based on an input matrix containing the biomarker composition of the taxonomic groups present in the samples. Further comments on the procedure followed will be described in the 'Results' section.

\section{RESULTS}

\section{PLFA composition of algal cultures}

The PLFA composition of each species was determined in duplicate. Average values are reported in Table 2. Standard deviations were always less than $5 \%$ of the average values and were not included. Of the 23 tested species, 9 were axenic (Table 1). In the non-axenic species, bacterial numbers were low and did not significantly alter the measured PLFA composition. This was corroborated by the fact that branched iso- or anteiso PLFA, which are found in bacteria only, were absent or present at very low abundance. The PLFA composition of the tested species is listed in Table 2 as a fraction of total PLFA. The most important differences and similarities will be discussed here.

In all tested species, $16: 0,16: 1 \omega 7 \mathrm{c}, 18: 1 \omega 9 \mathrm{c}$ and $18: 2 \omega 6 \mathrm{c}$ were present, although the relative abundance varied considerably and the latter 2 were present in the Bacillariophyceae in small amounts only. Interesting and useful differences occurred in the presence and relative abundance of 14:0, poly-unsaturated fatty acids (PUFA) with a chain length of 16 (16PUFA) and 18 (18PUFA) carbon atoms, 20:4 $66,20: 5 \omega 3$ and 22:6 $\omega 3$.

The Chlorophyceae and the Trebouxiophyceae differed from the other taxa by lacking PUFA longer than 18 carbon atoms and having no or only negligible amounts of 14:0. Both taxa had a small con-

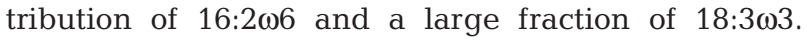
The Trebouxiophyceae contained a considerable

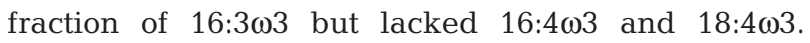
Of the Trebouxiophyceae tested, 1 (Chlorella autotrophica), contained 20:0. 16:3 103 was only a minor fraction in the Chlorophyceae, whereas it was a major component in the Trebouxiophyceae. Instead,

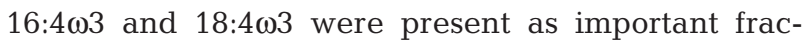
tions in the Chlorophyceae. The PLFA content of the Prasinophyceae was similar to that of the Chlorophyceae, but contained in addition the long fatty

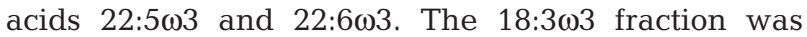
only 30 to $50 \%$ of that found in the 2 other Chlorophyte taxa.

The Bacillariophyceae were characterized by a relatively large fraction of $14: 0$ and the occurrence of

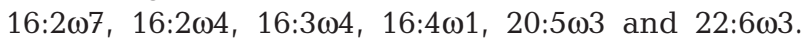
$18: 4 \omega 3$ comprises only a minor fraction in most Bacillariophyceae and the contribution of 18:3 $\omega 3$ was less than $1 \%$ in all species tested. The Cryptophyceae contain only PLFA that are also found in either the Chlorophyta (Chlorophyceae, Trebouxiophyceae and Prasinophyceae) or the Bacillariophyceae. Important

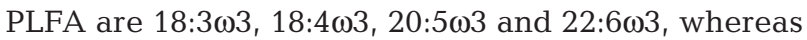
14:0 is found in low amounts. In the Rhodophyceae

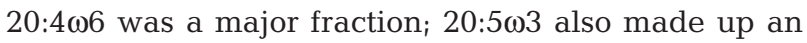
important fraction of the PLFA in this group and 16PUFA were lacking.

The Dinophyceae had a PLFA composition similar to that of the Cryptophyceae. Remarkable is the low contribution of 16:107c and of 20:5 103 in Heterocapsa triquetra, 1 of the 2 tested species. The Dinophyceae contain 2 PLFA that were not found in any of the taxa described above, namely 18:5 13 and an unidentified PUFA with a chain length of 20 carbon atoms. The chain length was deduced from retention time, mass spectra indicated that this PLFA is a PUFA. This PLFA is designated 20:x $\omega x$

In the Haptophyta, 2 groups seemed to be present, with one group resembling the Dinophyceae and the other more closely resembling the Bacillariophyceae.

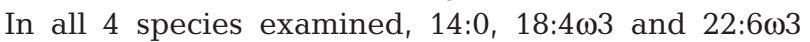
were found; $18: 5 \omega 3$ and the same $20: \mathrm{x} \omega \mathrm{x}$ as found in the Dinophyceae were present in Emiliania huxleyi and Phaeocystis globosa, but absent in Pavlova lutheri and Isochrysis sp.. The latter 2 species contained a high percentage of 20:5 13 , whereas this was present only in a very low amount in the former 2 species. In contrast to the Bacillariophyceae, Haptophyta did not contain 16PUFA. These 2 groups in the Haptophyta will be designated Haptophyta I (E. huxleyi and P. globosa) and Haptophyta II (P. lutheri and Isochrysis sp.) respectively. 


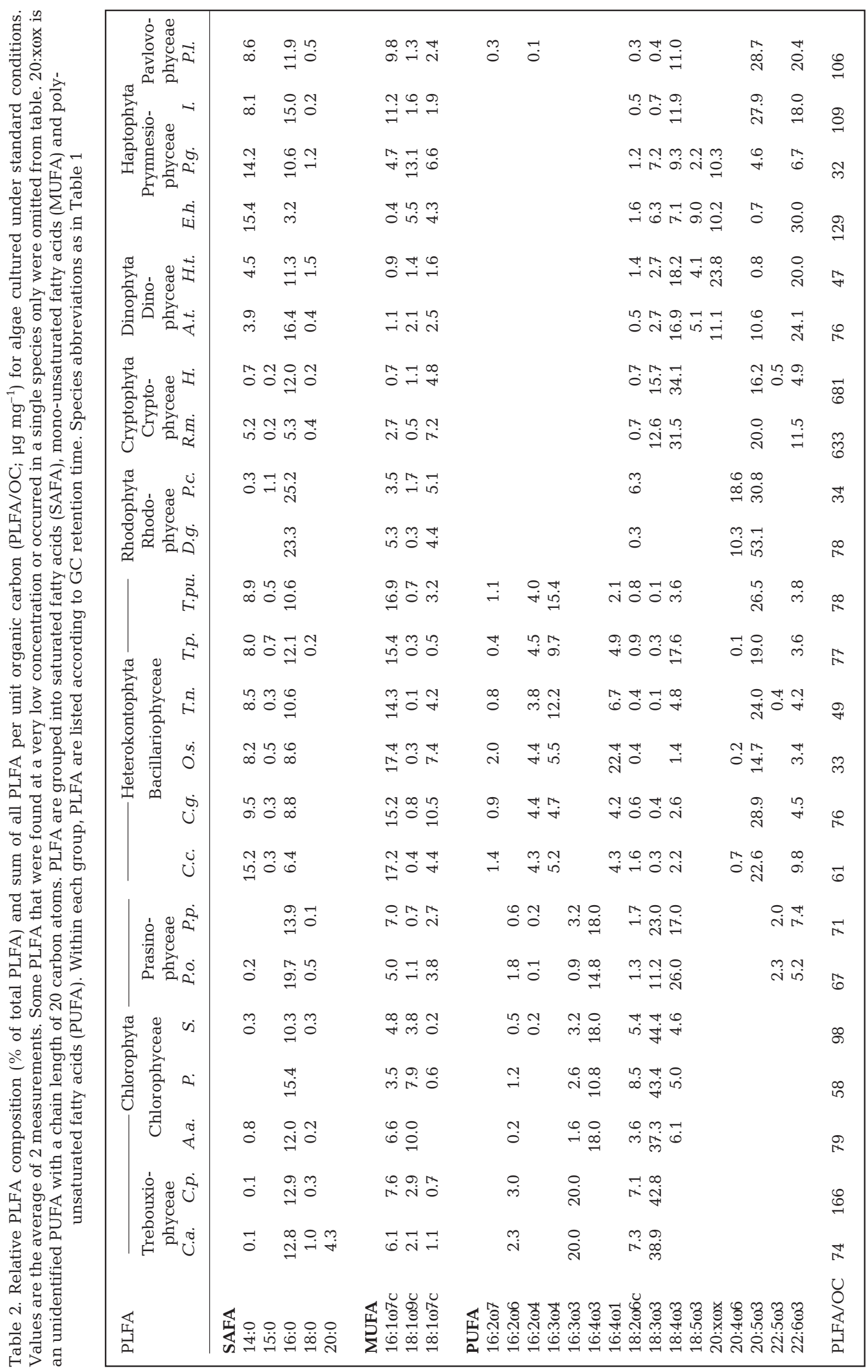




\section{Pigment composition of algal cultures}

The pigment composition of the species for which the PLFA composition is described above was measured, but is not discussed in detail here. The results agreed well with general data on the pigment composition of microalgae. Remarkable was that our strain of Phaeocystis globosa contained only a minute amount of 19'-hexanoyloxyfucoxanthin, a pigment which is often used as a biomarker for this species.

\section{a}

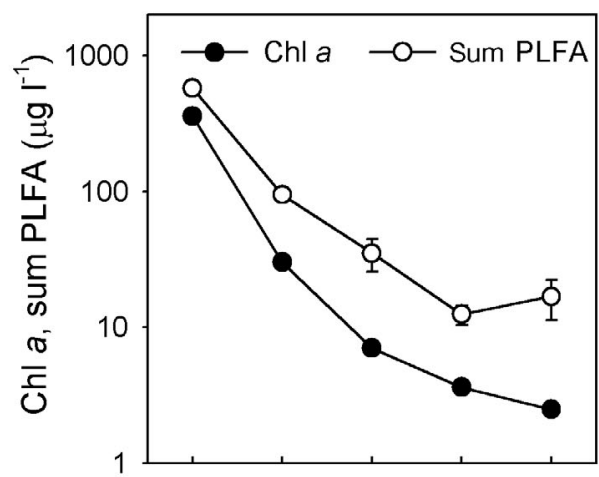

b

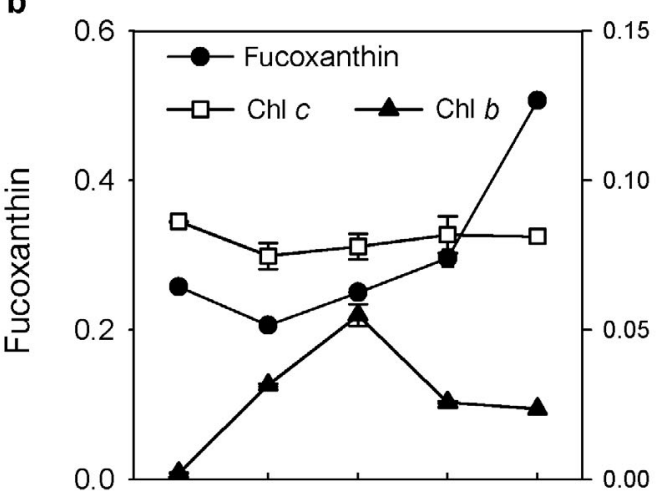

C

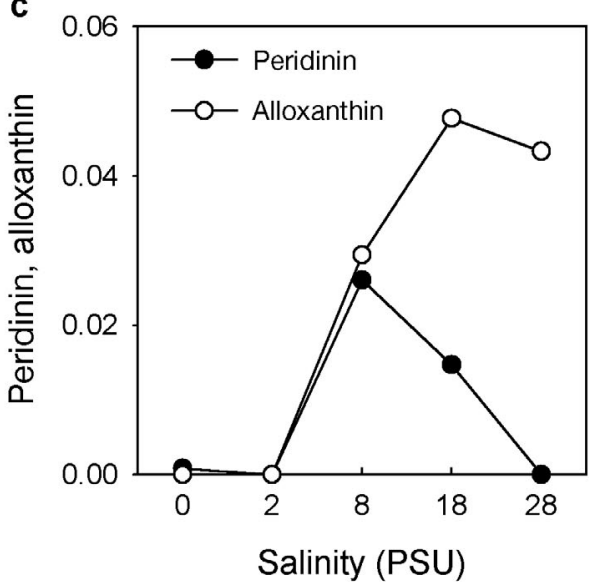

\section{PLFA and pigment in the Scheldt Estuary}

The variations in PLFA and pigment concentration and composition are shown for July 2003 in Fig. 2. The pigment data are averages of 2 samples per station, PLFA data averages of 8 samples per station. A large decline in biomass from freshwater to high-salinity water was apparent from the concentrations of both chlorophyll a (chl a) and total PLFA (Fig. 2a). In addition to this variation in biomass, the
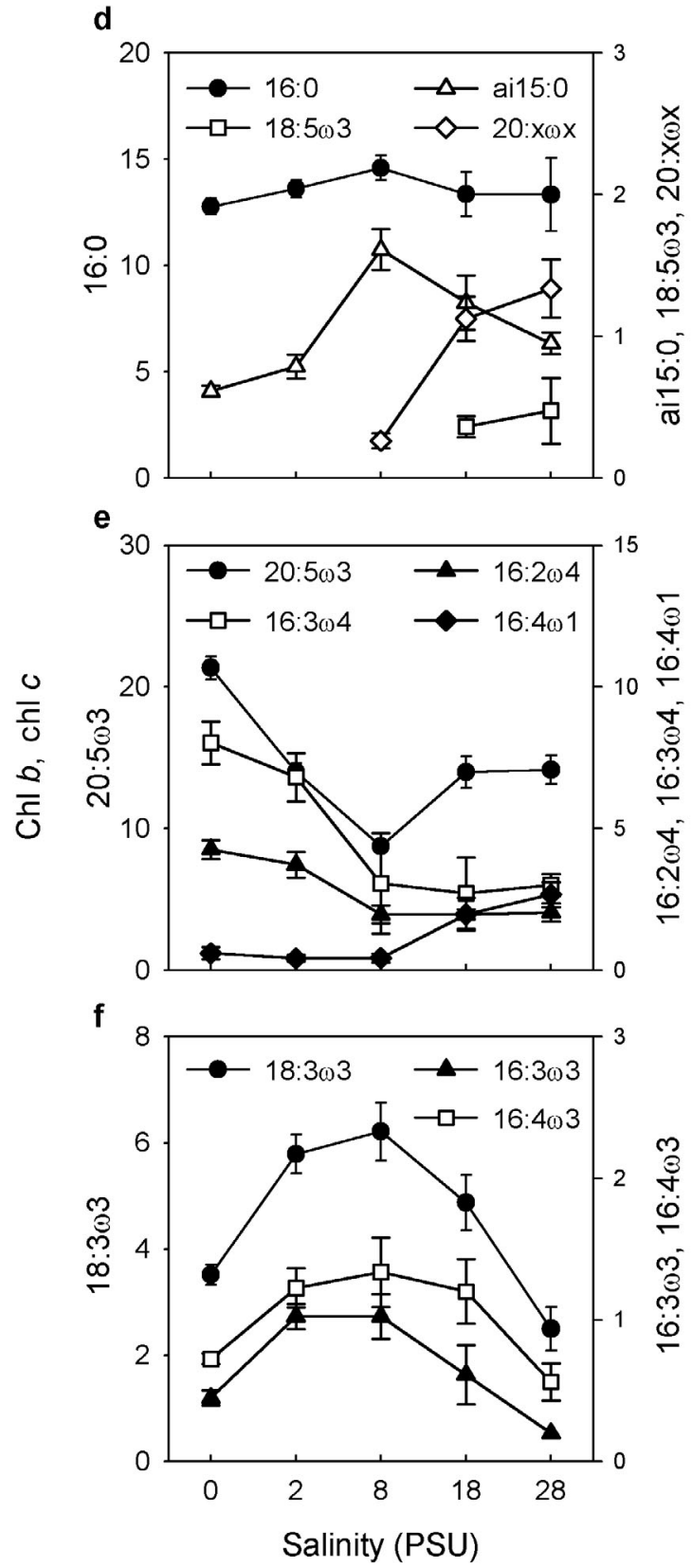

Fig. 2. Pigments and PLFA concentrations in the Scheldt Estuary in July 2003. (a) Chlorophyll a (chl a) and total PLFA ( $\mu$ g $\mathrm{l}^{-1}$ ); $(\mathrm{b}, \mathrm{c})$ pigment concentrations relative to $\mathrm{chl} a_{\text {; }}(\mathrm{d}-\mathrm{f})$ PLFA contribution as percentage of total PLFA 
pigment and PLFA composition varied between the stations.

Pigments are shown relative to chl $a$ in Fig. 2b,c. At all stations, fucoxanthin was the most abundant pigment. Its relative abundance increased with increasing salinity. Chl $C_{1}$, which is the sum of $\mathrm{chl} C_{1}$ and $\mathrm{chl} C_{2}$, varied little. Both fucoxanthin and $\mathrm{chl} c$ are found in the Bacillariophyceae, but are also present in other taxa such as the Haptophyta. Chl $b$, which is present in all Chlorophyta, increased from 0 to 8 PSU and returned to lower values at 18 and 28 PSU (Fig. 2b). Peridinin, characteristic for some (but not all) Dinophyceae, was found only in appreciable concentrations at 8 and 18 PSU. Peridinin was also detected at 0 and 2 PSU, but concentrations were very low. Alloxanthin is found in the Cryptophyceae and was detected at 8, 18 and 28 PSU (Fig. 2c). Pigments characteristic for cyanobacteria (such as zeaxanthin), or for some (but not all) Haptophyta (such as 19'-hexanoyloxyfucoxanthin and chl $C_{3}$ ) were not detected.

Individual PLFA concentrations are expressed as a percentage of total PLFA in Fig. 2d-f. A large number of different PLFA were detected; only the most important or those most useful as biomarker are shown. The PFLA 16:0 was present at an abundance of 13 to $15 \%$ of total PLFA and its contribution varied little between the stations (Fig. 2d). Branched fatty acids are characteristic for gram-positive bacteria (e.g. White et al. 1996). The fraction of the branched PLFA ai15:0 showed a maximum at 8 PSU (Fig. 2d) and was lower both at higher and lower salinities; 2 other branched PLFA (i15:0 and i16:0) followed similar dynamics (data not shown); $18: 1 \omega 7 \mathrm{C}$ showed a similar maximum at intermediate salinity to the branched fatty acids (data not shown). Gram-negative bacteria usually contain a large fraction of 18:1 $107 \mathrm{C}$ (White et al. 1996), although this PLFA is present as a minor fraction in many algal species as well (Table 2). We found 18:5 $\omega 3$ and 20:x $\omega x$ (both indicating the presence of Dinophyceae and Haptophyta I) at only the 3 highest salinities, with their abundance increasing with increasing salin-

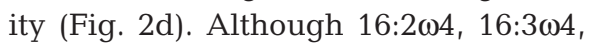

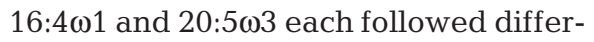
ent dynamics as a function of salinity, all probably originate from the Bacillariophyceae (Fig. 2e). The PLFA 16: 3 $\omega 3$, $16: 4 \omega 3$ and $18: 3 \omega 3$, all possibly originating from the Chlorophyta, increased from 0 to 8 PSU and decreased from 8 to 28 PSU (Fig. 2f). Other PLFA detected

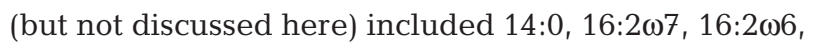

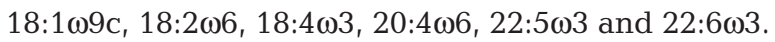

In April and October the biomass concentration was lower than in July; total PLFA at 0 PSU was 59 and $42 \%$ of the concentration in July respectively. For chl $a$, these values were 45 and $40 \%$ respectively of the concentration in July. The large decline in biomass, the fractional abundance of PLFA and pigments, and the changes along the salinity gradient were largely similar to the data shown for July in Fig. 2. Variations in the relative abundance of fucoxanthin, $\mathrm{chl} c$ and $\mathrm{chl} b$ in April and October were similar to July. There was some variation in alloxanthin and peridinin, but these are reflected in the group abundance shown in Fig. 3a, which was estimated from the pigment composition. The variations in the relative abundance of 16:2 14 ,

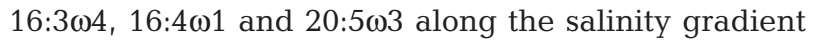
were similar in April and October. Increases in 18:5 $\omega 3$

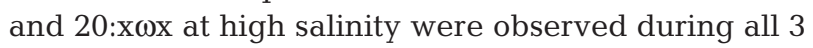
sampling campaigns, but in April the increase was much larger than in July. This coincided with a major bloom of Phaeocystis sp. at the mouth of the estuary (revealed by microscopic observations and visible to the naked eye). In October the increases in 18:503 and 20:x $\omega \mathrm{x}$ were of similar magnitude to those in July. The bloom of Phaeocystis sp. in April did not lead to a recognizable change in pigment composition. Differences were observed in the PLFA that most probably origi-

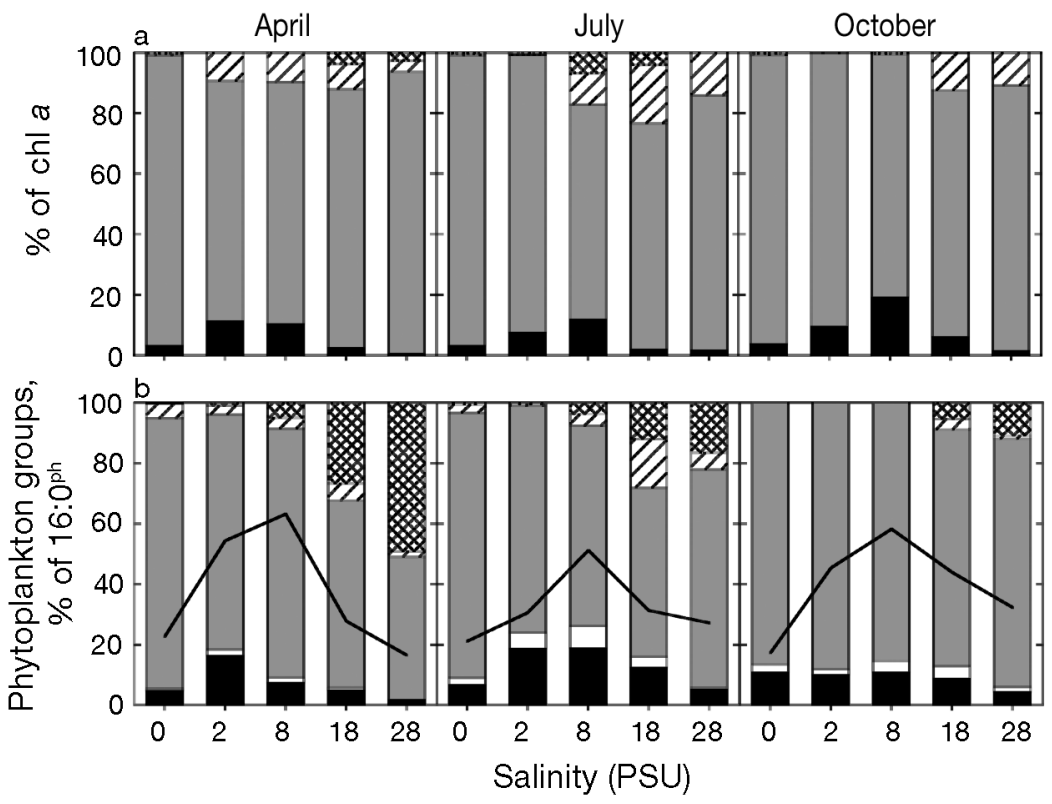

Fig. 3. Relative phytoplankton group abundance estimated using CHEMTAX. (a) Analysis based on pigment data, group abundance expressed as \% contribution to chl a; black shading: Chlorophyta; gray: Bacillariophyceae; hatched: Cryptophyceae; cross-hatched: Dinophyceae. (b) Analysis based on PLFA, group abundance expressed as \% contribution to 16:0 (bacteria) or \% contribution to 16:0 from photosynthetic groups $\left(16: 0^{\mathrm{ph}}\right)$; curve: bacteria; black shading: Chlorophyceae; white: Trebouxiophyceae; gray: Bacillariophyceae; hatched: Cryptophyceae; cross-hatched: Dinophyceae and HaptophytaI combined 


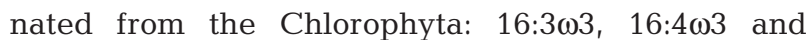
18:3 $\omega 3$ did not display a maximum at intermediate salinity in April and October as they did in July and the variation between stations was more variable.

\section{Group abundance}

The matrix factorization program CHEMTAX was used to estimate group abundance from the pigment and PLFA composition. Pigment and PLFA data in combination with microscopic observations were used to decide which taxa should be added to the input ratio matrix. The input ratio matrices for both pigment and PLFA data are shown in Table 3. The culture data for PLFA composition (Table 2) were used to construct the PLFA input matrices for the photosynthetic taxa. The PLFA composition of marine sediments was assumed to approximate the PLFA composition of the bacterial community of the water column, and an average bacterial PLFA signature was calculated from the data of Rajendran et al. (1992) and Stoeck et al. (2002). The pigment input matrix is based on the pigment composition of the same species for which the PLFA composition was determined. The data were grouped per station, and group abundance was estimated separately for each station using CHEMTAX.

Relative group abundance estimated from the pigment data is shown as the contribution of each group to chl $a$ in Fig. 3a, and group abundance estimated from the PLFA data in Fig. 3b, which shows the relative abundance of bacteria as a curve, representing the percent contribution of bacteria to 16:0. To facilitate a comparison with the results from the pigment data, the results for the photosynthetic taxa were recalculated as percent contribution to $16: 0$ of photosynthetic taxa only $\left(16: 0^{\mathrm{ph}}\right)$.

Both methods indicated that the Bacillariophyceae are always the most important group of algae in the Scheldt estuary. Chlorophyta make a minor contribution, varying from 1 to $19 \%$ of chl a and 2 to $23 \%$ of $16: 0^{\mathrm{ph}}$. Using PLFA, the Chlorophyta could be separated into Chlorophyceae and Trebouxiophyceae. According to the CHEMTAX results, the Chlorophyceae were always the dominant green algae group. Cryptophyceae were easily recognizable among the pigment data by their pigment alloxanthin, and contributed between 0 and $19 \%$ of chl $a$. Although this group did not contain any unique PLFA, their presence was indicated using CHEMTAX at the same stations where the Cryptophyceae were present according to the pigment analysis (compare Fig. 3a,b). Peridinin-containing Dinophyceae made a minor contribution to chl a based on the pigment data, but these data cannot be easily compared with the PLFA data, since the PLFA composition of the Dinophyceae was similar to that of the Haptophyta I, and these 2 groups were added as a combined group in the PLFA analysis. The abundance of this group increased with salinity. Haptophyta I includes the bloom-forming Phaeocystis sp. and in April the bloom of Phaeocystis sp. in the mouth of the estuary was clearly recognizable from the PLFA data. This bloom was not obvious from the pigment data, where the contribution of Phaeocystis sp. would have been included in the Bacillariophyceae.

CHEMTAX adapts the input ratio file (within limits set by the user) to best fit the field data. The adapted PLFA ratio file of 28 PSU is shown in Table 3 as an example. The ratio file was mainly adapted by CHEMTAX for the Bacillariophyceae and the bacteria. The relative abundance of $16: 2 \omega 4,16: 3 \omega 4$ and $16: 4 \omega 1$ changed such that it reflected the variations observed in the estuary. In a first analysis, the Chlorophyceae were added as the only representative of the Chlorophyta. This caused the ratio file to be adapted such that the PLFA composition of the group comprised an average of the PLFA composition of the Chlorophyceae and the Trebouxiophyceae. This led us to repeat the analysis, this time including both taxa as separate groups, even though this cannot be verified by pigment data or cell counts. Only results from this second analysis are shown herein.

The outcome of the CHEMTAX analysis changed little when non-unique PLFA like 18:169c were left out or when PLFA present only in small fractions like $16: 2 \omega 7$ or $16: 2 \omega 6$ were added. We chose to analyze the data per station, since this caused the ratio file to be adapted such that the variations observed in the estu-

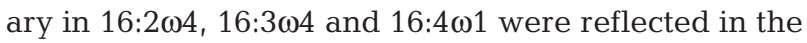
adapted ratio file. However, when all the data were analyzed in a single file instead of dividing the data per station, this had little effect on the outcome. The only group often affected by different fitting options was the Cryptophyceae, probably because this group lacks unique biomarkers.

The choice of the PLFA composition of marine sediments to define bacteria is arguably selective. To investigate the magnitude of the error introduced by not using the proper PLFA signature, we repeated the fitting procedure with the PLFA composition from drinking water (Keinänen et al. 2002). The PLFA signature differed from that in Table 3 by containing less branched fatty acids and more $18: 1 \omega 7 \mathrm{c}$. Using this alternative PLFA composition of bacteria, we found an increase in the contribution of bacteria to $16: 0$ of maximally $26 \%$ and an average difference of $18 \%$. The variations along the salinity gradient, with a maximum in bacterial abundance at 2 and 8 PSU, did not change. 
Table 3. Input ratio matrices for pigments and PLFA used for CHEMTAX analysis, and adapted ratio matrix for PLFA at 28PSU

\begin{tabular}{|c|c|c|c|c|c|c|}
\hline PLFA & $\begin{array}{l}\text { Chloro- } \\
\text { phyceae }\end{array}$ & $\begin{array}{l}\text { Trebouxio- } \\
\text { phyceae }\end{array}$ & $\begin{array}{l}\text { Bacillario- } \\
\text { phyceae }\end{array}$ & $\begin{array}{l}\text { Crypto- } \\
\text { phyceae }\end{array}$ & $\begin{array}{l}\text { Dinophyceae } \\
\text { \& Haptophyta I }\end{array}$ & Bacteria \\
\hline \multicolumn{7}{|c|}{ Input ratio matrix } \\
\hline i14:0 & 0 & 0 & 0 & 0 & 0 & 0.098 \\
\hline $14: 00$ & 0.046 & 0.013 & 0.806 & 0.335 & 0.736 & 0.334 \\
\hline i15:0 & 0 & 0 & 0 & 0 & 0 & 0.332 \\
\hline ai15:0 & 0 & 0 & 0 & 0 & 0 & 0.493 \\
\hline $15: 00$ & 0 & 0 & 0.041 & 0.018 & 0.112 & 0.111 \\
\hline i16:0 & 0 & 0 & 0 & 0 & 0 & 0.110 \\
\hline $16: 00$ & 1 & 1 & 1 & 1 & 1 & 1 \\
\hline $16: 1 \omega 7 \mathrm{C}$ & 0.402 & 0.534 & 1.681 & 0.196 & 0.194 & 0.667 \\
\hline $16: 2 \omega 4$ & 0 & 0 & 0.455 & 0 & 0.091 & 0 \\
\hline $16: 3 \omega 4$ & 0 & 0 & 0.743 & 0 & 0 & 0 \\
\hline $16: 3 \omega 3$ & 0.196 & 1.549 & 0 & 0 & 0 & 0 \\
\hline $16: 4 \omega 3$ & 1.260 & 0 & 0 & 0 & 0 & 0 \\
\hline $16: 4 \omega 1$ & 0 & 0 & 0.676 & 0 & 0 & 0 \\
\hline $18: 1 \omega 9 \mathrm{C}$ & 0.577 & 0.197 & 0.054 & 0.093 & 0.517 & 0.137 \\
\hline $18: 1 \omega 7 \mathrm{C}$ & 0.032 & 0.069 & 0.453 & 0.692 & 0.365 & 0.384 \\
\hline $18: 2 \omega 6 c$ & 0.460 & 0.558 & 0.083 & 0.080 & 0.101 & 0.094 \\
\hline $18: 3 \omega 3$ & 3.335 & 3.178 & 0 & 1.633 & 0.448 & 0 \\
\hline $18: 4 \omega 3$ & 0.421 & 0 & 0.519 & 3.777 & 1.207 & 0.000 \\
\hline $18: 5 \omega 3$ & 0 & 0 & 0 & 0 & 0.390 & 0 \\
\hline $20: x \omega x$ & 0 & 0 & 0 & 0 & 1.308 & 0 \\
\hline $20: 5 \omega 3$ & 0 & 0 & 2.272 & 2.282 & 0.358 & 0 \\
\hline $22: 6 \omega 3$ & 0 & 0 & 0.483 & 1.311 & 1.596 & 0 \\
\hline \multicolumn{7}{|c|}{ Adapted ratio matrix PLFA 28 PSU } \\
\hline i14:0 & 0 & 0 & 0 & 0 & 0 & 0.128 \\
\hline $14: 00$ & 0.046 & 0.013 & 0.723 & 0.335 & 0.736 & 0.334 \\
\hline i15:0 & 0 & 0 & 0 & 0 & 0 & 0.309 \\
\hline ai15:0 & 0 & 0 & 0 & 0 & 0 & 0.361 \\
\hline $15: 00$ & 0 & 0 & 0.037 & 0.018 & 0.065 & 0.111 \\
\hline i16:0 & 0 & 0 & 0 & 0 & 0 & 0.108 \\
\hline $16: 00$ & 1 & 1 & 1 & 1 & 1 & 1 \\
\hline $16: 1 \omega 7 \mathrm{c}$ & 0.402 & 0.534 & 1.487 & 0.196 & 0.194 & 0.667 \\
\hline $16: 2 \omega 4$ & 0 & 0 & 0.347 & 0 & 0.091 & 0 \\
\hline $16: 3 \omega 4$ & 0 & 0 & 0.524 & 0 & 0 & 0 \\
\hline $16: 3 \omega 3$ & 0.196 & 1.549 & 0 & 0 & 0 & 0 \\
\hline $16: 4 \omega 3$ & 1.260 & 0 & 0 & 0 & 0 & 0 \\
\hline $16: 4 \omega 1$ & 0 & 0 & 0.515 & 0 & 0 & 0 \\
\hline $18: 1 \omega 9 c$ & 0.577 & 0.197 & 0.048 & 0.093 & 0.738 & 0.137 \\
\hline $18: 1 \omega 7 \mathrm{C}$ & 0.032 & 0.069 & 0.389 & 0.692 & 0.365 & 0.384 \\
\hline $18: 2 \omega 6 c$ & 0.460 & 0.558 & 0.088 & 0.080 & 0.101 & 0.094 \\
\hline $18: 3 \omega 3$ & 3.335 & 3.178 & 0 & 1.633 & 0.448 & 0 \\
\hline $18: 4 \omega 3$ & 0.421 & 0 & 0.466 & 3.777 & 1.157 & 0 \\
\hline $18: 5 \omega 3$ & 0 & 0 & 0 & 0 & 0.390 & 0 \\
\hline $20: x \omega x$ & 0 & 0 & 0 & 0 & 1.187 & 0 \\
\hline $20: 5 \omega 3$ & 0 & 0 & 2.103 & 2.282 & 0.358 & 0 \\
\hline $22: 6 \omega 3$ & 0 & 0 & 0.433 & 1.311 & 1.510 & 0 \\
\hline \multicolumn{7}{|c|}{ Input ratio matrix pigments } \\
\hline Chl a & 1 & & 1 & 1 & 1 & \\
\hline Chl $b$ & 0.222 & & 0 & 0 & 0 & \\
\hline $\mathrm{Chl} \mathrm{C}$ & 0 & & 0.089 & 0.070 & 0.120 & \\
\hline Diadinoxanthin & 0 & & 0.058 & 0 & 0.129 & \\
\hline Fucoxanthin & 0 & & 0.311 & 0 & 0 & \\
\hline Lutein & 0.200 & & 0 & 0 & 0 & \\
\hline Peridinin & 0 & & 0 & 0 & 0.409 & \\
\hline Alloxanthin & 0 & & 0 & 0.259 & 0 & \\
\hline
\end{tabular}

The higher estimation of bacterial abundance had little effect on the contribution of the photosynthetic taxa to $16: 0^{\mathrm{ph}}$. The maximum change was $-9.5 \%$ of $16: 0^{\mathrm{ph}}$ (for the Bacillariophyceae) whereas the average change was $-4.5 \%$. The average change for the other groups was $1.1 \%$. 


\section{DISCUSSION}

The PLFA composition we determined in algal cultures (Table 2) agreed well with the total lipid-derived fatty acid composition of the same taxonomic groups in the literature (e.g. Volkman et al. 1989, Viso \& Marty 1993, Brown et al. 1996, Renaud et al. 2002). Most photosynthetic taxa had a well-defined PLFA composition, with variations occurring in the relative abundance of PLFA and not in their absence or presence. An exception was the Haptophyta, in which 2 different PLFA types were found. Phylogenetic trees show that the division of Haptophyta is split into 2 classes, being the Pavlovophyceae (which contains all Pavlova species), and the Prymnesiophyceae containing all other haptophyte species (Edvardsen et al. 2000). Thus, Pavlova sp. and Isochrysis sp. belong to different taxa, even though their PLFA signature is similar. Pigment data also show the Haptophyta to comprise a heterogeneous group; Zapata et al. (2004) recognized 8 different types of Haptophyta based on pigment data.

The PLFA composition of Haptophyta I resembled that of the 2 Dinophyceae; for this reason these 2 groups were combined for the estimation of group abundance. The pigment peridinin is unique to the Dinophyceae. However, Dinophyceae are also known that lack peridinin but contain 19'-hexanoyloxyfucoxanthin and chl $c$, alloxanthin and $\mathrm{chl} c$, fucoxanthin, chl $c_{1}$ and chl $c_{2}$, or chl $b$ (Jeffrey \& Wright 2006). These different pigment types in the Dinophyceae are the result of multiple endosymbiotic events involving Haptophyta, Cryptophyceae, Bacillariophyceae or Chlorophyta, respectively as the organisms from which the Dinophyceae acquired their chloroplasts. Possibly, the

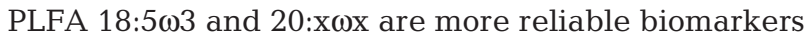
for the Dinophyceae than pigments, but more species need to be tested before this can be ascertained. An interesting point in this respect is that the evolutionary pathways of pigments and of PLFA are not necessarily the same. Phospholipids are membrane lipids, most of which originate in the host cell, while pigments are restricted to the chloroplasts and thus originate in the endosymbiont. Algae acquired their chloroplasts by multiple endosymbiotic events (Jeffrey \& Wright 2006), and thus the evolutionary pathways of PLFA and pigments can very well be different.

Several studies have described variations in fatty acid composition in natural waters and have used fatty acid composition to describe phytoplankton community structure (Shin et al. 2000, Reuss \& Poulsen 2002, Boschker et al. 2005). Mostly a qualitative or semiquantitative approach is used to derive information on phytoplankton composition. Boschker et al. (2005)

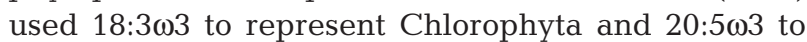
represent Bacillariophyceae. Other authors have used ratios of fatty acids to indicate the dominance of certain taxonomic groups, such as high ratios of $16: 1 \omega 7 \mathrm{c} / 16: 0$ and $\Sigma \mathrm{C} 16 / \Sigma \mathrm{C} 18$ as an indication for Bacillariophyceae abundance (Shin et al. 2000, Reuss \& Poulsen 2002) or

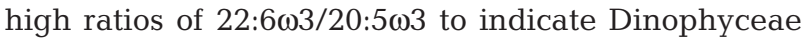
(Budge \& Parrish 1998).

We chose to use the matrix factorization program CHEMTAX to analyze the field data. This program has become increasingly popular in recent years for analyzing pigment data. An important advantage of CHEMTAX over the use of individual fitted algorithms for each group is that information on all biomarkers can be used, and that during the fitting procedure the program adapts the relative biomarker composition of the taxonomic groups. The rationale for adapting the ratio file is that the biomarker composition can vary in response to changes in environmental parameters and that the biomarker ratios need to be optimized to the actual biomarker composition of the taxonomic groups present in the sample.

In our analyses, the ratio file (Table 3) was adapted such that the variations in the Bacillariophyceae PLFA $16: 2 \omega 4,16: 3 \omega 4$ and $16: 4 \omega 1$ were reflected in the adapted ratio files. This was the main reason for analyzing the data per station. Adaptations by CHEMTAX in the ratio file were also the reason for adding the Chlorophyceae and the Trebouxiophyceae as separate taxa, even though this could not be verified by pigment data or cell counts.

As pointed out by Mackey et al. (1996), what is obtained after a CHEMTAX analysis is an estimate of the abundance of taxonomic groups with the biomarker composition specified in the ratio file. This means that taxonomic groups might be 'hidden' in or combined with other taxonomic groups. This was most obvious for the bloom of Phaeocystis sp. in April (Fig. 3), which was easily recognizable from the PLFA data but was not clear from the pigment data. 19 '-hexanoyloxyfucoxanthin is a well-known biomarker pigment for Phaeocystis sp. (Zapata et al. 2004). However, the local strain of Phaeocystis sp. contains only minute amounts of this pigment (Vaulot et al. 1994, N. Dijkman pers. obs.), and the chl a from Phaeocystis sp. would have been included in the Bacillariophyceae in Fig. 3a.

Mackey et al. (1996), and more recently Lewitus et al. (2005), have stressed the importance of using data in the input ratio files that closely approach the biomarker composition of the groups actually present in the field samples. Lewitus et al. (2005) found that results improved significantly when the biomarker composition of estuarine species was used to estimate the group composition from pigment data in an estuary compared to using the biomarker composition published by Mackey et al. (1996), which was based on 
marine species. With this in mind, we selected species either isolated from the Scheldt estuary or laboratory strains of species relevant to the estuary.

The culture conditions were chosen to approximate environmental conditions in the estuary. The cultivation temperature of $15^{\circ} \mathrm{C}$ was in the middle of the temperature range of the estuary, which was 11,20 and $14^{\circ} \mathrm{C}$ in April, July and October respectively. Similarly, the relatively low irradiance of $40 \mu \mathrm{mol} \mathrm{m} \mathrm{m}^{-2} \mathrm{~s}^{-1}$ was considered appropriate for this very turbid estuary. The fatty acid composition of algae is known to vary in response to changes in environmental parameters such as temperature (Zhu et al. 1997), irradiance (Brown et al. 1996) and growth phase (Brown et al. 1996, Zhu et al. 1997). However, most literature data concern total fatty acids and information on PLFA is scarce. A 6-fold increase in irradiance from 26 to $170 \mu \mathrm{mol} \mathrm{m}^{-2} \mathrm{~s}^{-1}$ led to changes of maximally $3 \%$ in the contribution of individual PLFA to total PLFA in Thalassiosira pseudonana (Dijkman, unpubl. data). Zhu et al. (1997) reported differences of maximally $6 \%$ in PLFA composition for Isochrysis galbana grown at either 15 or $30^{\circ} \mathrm{C}$. The variations between species are in the same order of magnitude (Table 2) and we did not try to simulate the effects of these changes on the estimated group abundance.

Especially in a net heterotrophic estuary such as the Scheldt (Heip et al. 1995), bacteria make an important contribution to the PLFA composition. Obtaining a proper estimation of the PLFA composition of the Scheldt estuary posed a problem. In turbid estuaries such as the Scheldt, a major fraction of bacteria is associated with particles. In addition, many of the freeliving bacteria are also trapped by the filters, whose pores are rapidly clotted when water with a high particle-load is filtered (Selje \& Simon 2003). Thus, even though many bacteria are small enough to pass through the pores of the glass fiber filters, a large fraction of the bacteria will be retained on the filters. This prevents separation of bacteria from eukaryotes by size-fractionation, which might otherwise be used to obtain the PLFA composition of the bacterial community. The PLFA composition of bacteria that we used in the CHEMTAX matrix (Table 3 ) is an approximation and, as discussed in the 'Results', this has added uncertainty to our results. Fortunately, this had little effect on the relative phytoplankton composition.

Zooplankton were ignored in our analysis, although some zooplankton were seen in the samples. It was assumed that their abundance was so low that their importance was minor compared to phytoplankton and bacteria. This assumption is supported by the good agreement between pigment and PLFA data. A possibility would have been to remove zooplankton by prefiltering the samples over a zooplankton filter. We chose not to do this since many of the algal species formed large colonies similar in size to the zooplankton or were attached to larger particles and would thus also have been removed by a zooplankton filter.

The phytoplankton composition calculated from pigment and PLFA data (Fig. 3) is in good agreement with variations in phytoplankton composition along an estuarine salinity gradient in general and the Scheldt estuary in particular. Lemaire et al. (2002) measured the pigment composition in 9 European estuaries, 1 of which was the Scheldt estuary, and these authors reported that Bacillariophyceae were dominant in all estuaries. Other groups present were Chlorophyta, Cryptophycea and Dinophyceae, which agrees well with our results. A spring bloom of Phaeocystis sp. is a reoccurring phenomenon in many temperate marine waters (Schoemann et al. 2005) and is usually observed in spring in the Scheldt estuary at salinities higher than 18 PSU.

As the result of tidal forcing and the morphology of the estuary, the turbidity maximum of the Scheldt estuary is around 2 to 8 PSU. This high turbidity results in an unfavorable light climate for phytoplankton. Bacterial growth and relative abundance are usually high in this area (Heip et al. 1995). Despite the uncertainty in the fractional abundance of bacteria, the maximum abundance at intermediate salinity was always reproducible and independent of the ratio file used.

It should be remembered that the results in Fig. 3 show the relative group abundance. Due to the large decrease in biomass from low to high salinity (see Fig. 2a), the absolute concentration of bacteria as well as that of most phytoplankton groups actually decreased from the freshwater site to the mouth of the estuary.

Some degree of uncertainty is inherent in comparisons of cell counts, pigment data and PLFA data, with errors being associated with all methods. Uncertainty in estimations of group abundance using CHEMTAX is commonly assumed to be in the range of $25 \%$ for individual groups (e.g Lewitus et al. 2005); this agrees well with the variation of maximally $26 \%$ in bacterial abundance that occurs when a different PLFA input ratio for the bacteria is used. We found the PLFA analysis to be more robust than the pigment analysis, probably due to the larger number of markers that can be included when PLFA are used. A different grouping of the field data or including a different number of biomarkers had remarkably little effect on the outcome, inducing variations of only a few percent. Part of the difference between pigment-derived and PLFA-derived group abundance was the result of normalizing the pigments to chl $a$ and PLFA to 16:0. Both chl $a$ and 16:0 per unit biomass vary between species and in response to changes in environmental parameters. 
Despite these uncertainties, the agreement between pigment and PLFA data was generally good. Compared to pigments, PLFA are less specific. Phospholipids are important membrane lipids in all cells and are not restricted to photosynthetic taxa. This can be an advantage, since information on non-photosynthetic taxa can also be derived (as in our data for the bacteria), but can also be a complication since few PLFA are unique to a single group. Our data on the Scheldt estuary show that PLFA can be a useful complement to pigment data. This was most obvious for the bloom of Phaeocystis sp., which was easily overlooked using the photosynthetic pigments, but showed up clearly in the PLFA analysis. It should be remembered that the specificity of a PLFA and selection of a PLFA as biomarker for a specific group will also depend on the taxa contributing to the PLFA composition of the sample. The results of the present study give us confidence that PLFA can be used in future applications such as the calculation of group-specific growth rates.

Acknowledgements. We thank E. Boschker, J. Peene, P. van Rijswijk, M. Houtekamer, J. Nieuwenhuize, U. Wollenzien, J. J. Middelburg and the crew of the RV 'Luctor' for their help and assistance during the measurements and M. Doeleman for the $18 \mathrm{~S}$ molecular sequencing. We also thank 3 anonymous reviewers whose remarks helped considerably to improve this manuscript. This work is part of a Flemish-Dutch cooperation for Sea Research (VLANEZO) and is financed by the Dutch Organization of Scientific Research (NWO 832.11.002 and 832.11.007) and the Fund for Scientific Research-Flanders (FWO). This is NIOO publication number 3920.

\section{LITERATURE CITED}

Badylak S, Phlips EJ (2004) Spatial and temporal patterns of phytoplankton composition in a subtropical coastal lagoon, the Indian River Lagoon, Florida, USA. J Plankton Res 26:1229-1247

Bligh EG, Dyer WJ (1959) A rapid method of total lipid extraction and purification. Can J Biochem Physiol 31:911-917

Boschker HTS (2004) Linking microbial community structure and functioning: stable isotope (13C) labeling in combination with PLFA analysis. In: Kowalchuk GA, deBruin FJ, Head IM, Akkermans AD, van Elsas JD (eds) Molecular microbial ecology manual II. Kluwer Academic Press, Dordrecht, p 1673-1688

Boschker HTS, Kromkamp JC, Middelburg JJ (2005) Biomarker and carbon isotopic constraints on bacterial and community structure and functioning in a turbid, tidal estuary. Limnol Oceanogr 50:70-80

Brown MR, Dunstan GA, Norwood SJ, Miller KA (1996) Effects of harvest stage on the biochemical composition of the diatom Thalassiosira pseudonana. J Phycol 32:64-73

Budge SM, Parrish CC (1998) Lipid biogeochemistry of plankton, settling matter and sediments in Trinity Bay, Newfoundland. II. Fatty acids. Org Geochem 29:1547-1559

Drenovsky RE, Elliott GN, Graham KJ, Scow KM (2004) Comparison of phospholipid fatty acid (PLFA) and total soil fatty acid methyl esters (TSFAME) for characterizing soil microbial communities. Soil Biol Biochem 36:1793-1800
Edvardsen B, Eikrem W, Green JC, Andersen RA, Moon-van der Staay SY, Medlin L (2000) Phylogenetic reconstructions of the Haptophyta inferred from 18S ribosomal DNA sequences and available morphological data. Phycologia 39:19-35

Garibotti IA, Vernet M, Kozlowski WA, Ferrario ME (2003) Composition and biomass of phytoplankton assemblages in coastal Antarctic waters: a comparison of chemotaxonomic and microscopic analyses. Mar Ecol Prog Ser 247: $27-42$

Gieskes WWC, Kraay GW (1983) Dominance of Cryptophyceae during the phytoplankton spring bloom in the central North Sea detected by HPLC analysis of pigments. Mar Biol 75:179-185

Guillard RRL, Ryther JH (1962) Studies of marine planktonic diatoms. I. Cyclotella nana Hustedt and Detonula confervacea (Cleve) Gran. Can. J Microbiol 8:229-239

Heip CHR, Goosen NK, Herman PMJ, Kromkamp J, Middelburg JJ, Soetaert K (1995) Production and consumption of biological particles in temperate tidal estuaries. Oceanogr Mar Biol Annu Rev 33:1-149

Hillebrand H, Dürselen CD, Kirschtel D, Pollingher U, Zohary $\mathrm{T}$ (1999) Biovolume calculation for pelagic and benthic microalgae. J Phycol 35:403-424

Hutchinson GE (1961) The paradox of the plankton. Am Nat 95:137-145

Jeffrey SW, Wright SW (2006) Photosynthetic pigments in marine microalgae: insights from cultures and the sea. In: Rao DVS (ed) Algal cultures, analogues of blooms and applications. Science Publishers, Enfield, p 34-90

Keinänen MM, Korhonen LK, Lehtola MJ, Miettinen IT, Martikainen PJ, Vartiainen T, Suutari MH (2002) The microbial community structure of drinking water biofilms can be affected by phosphorus availability. Appl Environ Microbiol 68:434-439

Koeman RPT, Brochard CJE, Fockens K, Verweij GL, Esselink $P$ (2004) Biomonitoring van fytoplankton in de Nederlandse zoute wateren 2003, Kite diagrammen. Koeman en Bijkerk, Ecologisch Onderzoek en Advies, Haren

Lemaire L, Abril G, de Wit R, Etcheber H (2002) Distribution of phytoplankton pigments in 9 European estuaries and implications for estuarine typology. Biogeochemistry 59: $5-23$

Lewitus AJ, Hymel SN, White DL, Tymowski RG, Geesey ME, Noble PA (2005) Adapting the CHEMTAX method for assessing phytoplankton taxonomic composition in southeastern U. S. estuaries. Estuaries 28:160-172

Mackey MD, Mackey DJ, Higgins HW, Wright SW (1996) CHEMTAX - a program for estimating class abundances from chemical markers: application to HPLC measurements of phytoplankton. Mar Ecol Prog Ser 144:265-283

Marinho MM, Rodrigues SV (2003) Phytoplankton of an eutrophic tropical reservoir: comparison of biomass estimated from counts with chlorophyll-a biomass from HPLC. Hydrobiologia 505:77-88

Menden-Deuer S, Lessard EJ (2000) Carbon to volume relationships for dinoflagellates, diatoms, and other protist plankton. Limnol Oceanogr 45:569-579

Pinkart HG, Ringelberg DB, Piceno YM, MacNaughton SJ, White DC (2002) Biochemical approaches to biomass measurements and community structure. In: Hurst CJ, Crawford RL, Knudsen GR, McInerney MJ, Stetzenbach LD (eds) Manual of environmental microbiology, 2nd edn. American Society for Microbiology Press, Washington, DC, p 101-113

Rajendran N, Matsuda O, Imamura N, Urushigawa Y (1992) Variation in microbial biomass and community structure 
in sediments of eutrophic bays as determined by phospholipid ester-linked fatty acids. Appl Environ Microbiol 58: 562-571

Renaud SM, Thinh L-V, Lambrinidis G, Parry DL (2002) Effect of temperature on growth, chemical composition and fatty acid composition of tropical Australian microalgae grown in batch cultures. Aquaculture 211:195-214

Reuss N, Poulsen LK (2002) Evaluation of fatty acids as biomarkers for a natural plankton community. A field study of a spring bloom and a post-bloom period off West Greenland. Mar Biol 141:423-434

Rijstenbil JW (2003) Effects of UVB radiation and salt stress on growth, pigments and antioxidative defence of the marine diatom Cylindrotheca closterium. Mar Ecol Prog Ser 254:37-48

Schlüter L, Møhlenberg F (2003) Detecting presence of phytoplankton groups with non-specific pigment signatures. J Appl Phycol 15:465-476

Schoemann V, Becquevort S, Stefels J, Rousseau V, Lancelot C (2005) Phaeocystis blooms in the global ocean and their controlling mechanisms: a review. J Sea Res 53:43-66

Selje N, Simon M (2003) Composition and dynamics of particle-associated and free-living bacterial communities in the Weser estuary, Germany. Aquat Microb Ecol. 30: 221-237

Shin KH, Hama T, Yoshie N, Noriki S, Tsunogai S (2000) Dynamics of fatty acids in newly biosynthesized phytoplankton cells and seston during a spring bloom off the west coast of Hokkaido Island, Japan. Mar Chem 70: $243-256$

Editorial responsibility: Victor de Jonge (Contributing Editor), Haren, The Netherlands
Stanier RY, Kunisawa R, Mandel M, Cohen-Bazire G (1971) Purification and properties of unicellular blue-green algae (order Chroococcales). Bacteriol Rev 35:171-205

Stoeck T, Kröncke I, Duineveld GCA, Palojärvi A (2002) Phospholipid fatty acid profiles at depositional and non-depositional sites in the North Sea. Mar Ecol Prog Ser 241:57-70

Underwood GJC, Kromkamp J (1999) Primary production by phytoplankton and microphytobenthos in estuaries. Adv Ecol Res 29:93-153

Vaulot D, Birrien JL, Marie D, Casotti R, Veldhuis MJW, Kraay GW, Chretiennot-Dinet M-J (1994) Morphology, ploidy, pigment composition, and genome size of cultured strains of Phaeocystis (Prymnesiophyceae). J Phycol 30: 1022-1035

Viso AC, Marty JC (1993) Fatty acids from 28 marine microalgae. phytochemistry 34:1521-1533

Volkman JK, Jeffrey SW, Nichols PD, Rogers GI, Garland CD (1989) Fatty acid and lipid composition of 10 species of microalgae used in mariculture. J Exp Mar Biol Ecol 128: $219-240$

White DC, Stair JO, Ringelberg DB (1996) Quantitative comparisons of in situ microbial biodiversity by signature biomarker analysis. J Ind Microbiol 17:185-196

Zapata M, Jeffrey SW, Wright SW, Rodriquez F, Garrido JL, Clementson L (2004) Photosynthetic pigments in 37 species (65 strains) of Haptophyta: implications for oceanography and chemotaxonomy. Mar Ecol Prog Ser 270:83-102

Zhu CJ, Lee YK, Chao TM (1997) Effects of temperature and growth phase on lipid and biochemical composition of Isochrysis galbana TK1. J Appl Phycol 9:451-457

Submitted: May 13, 2005; Accepted: March 26, 2006

Proofs received from author(s): September 27, 2006 